\title{
Acute dissection of the right ventricular outflow tract after balloon dilatation in a patient with previously corrected tetralogy of Fallot
}

\author{
M H D Danton, B Craig, D Gladstone
}

\begin{abstract}
Percutaneous balloon dilatation has been used successfully to dilate various stenoses occurring after repair of congenital heart disease. Acute dissection of a stenotic right ventricular outflow tract occurred after attempted balloon dilatation in a patient with previously corrected tetralogy of Fallot.
\end{abstract}

(Br Heart F 1994;72:203-204)

Recurrent obstruction of the right ventricular outflow tract (RVOT) is a recognised complication of repair of tetralology of Fallot. If, at the original repair, a transannular patch is used to augment the right ventricular outflow tract, differential growth between the patch

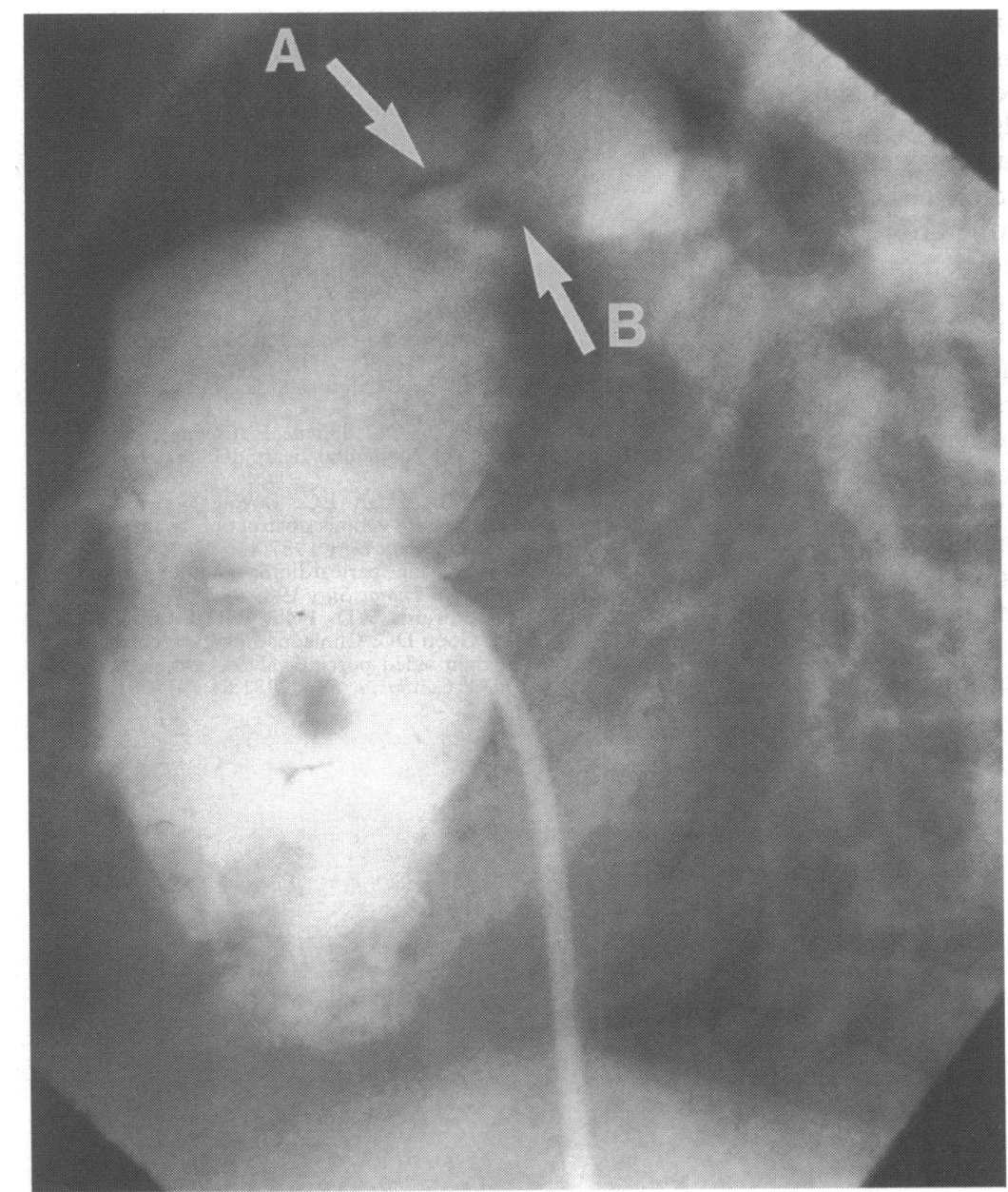

Figure 1 Cardiac catheterisation, with right ventricular injection, showing a dissected neointimial flap within the right ventricular outflow tract $(A)$ and the residual fibrous shelf of the pulmonary valve $(B)$. and the native pulmonary artery can result in recurrent obstruction. Reoperation with reconstruction of the outflow tract, is the usual management, but is associated with considerable mortality. In the presented case, recurrent stenosis of the RVOT developed at the level of the transannular patch. To avoid reoperation, percutaneous balloon dilatation was attempted, but resulted in dissection of a layer of neointima from the bovine pericardial transannular patch, exacerbating the obstruction and needing emergency surgery.

\section{Case report}

After a full term normal delivery, a $3.4 \mathrm{~kg}$ female infant became increasingly cyanosed. Investigations established the diagnosis of tetralogy of Fallot. Initial management consisted of palliation with a left modified Blalock-Taussig shunt at 4 weeks of age. Definitive surgery was performed at the age of 3 years. At operation the characteristic features of tetralogy of Fallot were present with atresia of the pulmonary valve. Repair included a transannular patch of bovine pericardium to augment the right ventricular outflow tract (RVOT).

After completion of the repair there was a small RVOT gradient of $20 \mathrm{~mm} \mathrm{Hg}$ with a right ventricular systolic pressure $60 \%$ of the systemic arterial pressure. Recovery was uneventful but follow up echocardiography showed a progressive rise in the pressure gradient of the RVOT.

Cardiac catheterisation, four years after the operation, showed discrete stenosis at the pulmonary annulus with a gradient of $70 \mathrm{~mm} \mathrm{Hg}$ and a right ventricular systolic pressure equal to systemic arterial pressure. Percutaneous balloon dilatation of the stenotic pulmonary annulus was attempted. A $15 \mathrm{~mm}$ balloon was placed across the annulus (annular size $=12 \mathrm{~mm}$ ) and inflated. No difficulty was encountered in crossing the pulmonary annulus with the catheter or in inflating the balloon.

After dilatation there was a sudden increase in the obstruction; the transannular gradient increased to $100 \mathrm{~mm} \mathrm{Hg}$ and right ventricular pressure became suprasystemic. The right ventricle dilated and contracted poorly; the patient became deeply cyanosed and hypotensive. A flap of tissue was seen in the RVOT and dissection of the RVOT diagnosed (figure (A)). 
The patient was stabilised and transferred to the operating theatre. After establishing cardiopulmonary bypass, the RVOT was explored. On the luminal surface of the bovine pericardium there was a thickened layer of neointimal peel. A dissection had occurred in the plane between this and the underlying bovine pericardium creating a flap that obstructed the right ventricular tract. Inadequate width of the original transannular patch and the presence of a residual fibrous shelf of pulmonary valve tissue (figure (B)) was thought to be the cause of the recurrent obstruction.

The dissected peel was excised along with the corresponding bovine pericardium and the residual pulmonary valve fibrotic ring. Autologous pericardium was then used to augment the RVOT patch. A satisfactory patent RVOT was achieved with a right ventricular systolic pressure after bypass of one third of the systemic arterial pressure. The patient made an uneventful recovery.

\section{Discussion}

Significant persistent or recurrent obstruction of the RVOT needing reoperation, occurs in $6 \%-9 \%$ of patients after corrective repair of tetralogy of Fallot. ${ }^{2}$ Reoperation for relief of that obstruction is associated with a considerable hospital mortality $(6 \%-20 \%) .^{3}$ Balloon dilatation has been used successfully to dilate various stenoses occurring throughout the cardiovascular system and is now the treatment of choice for congenital pulmonary valve stenosis. ${ }^{4}$ It has also been successful in the management of recurrent stenosis occurring in previously corrected congenital heart disease, thus avoiding reoperation..$^{56}$

Satisfactory surgical correction of tetralogy of Fallot commonly needs relief of the obstruction of the RVOT with a transannular patch. In this patient the patch material was bovine pericardium preserved in gluteraldehyde. This has been used widely in the repair of various congenital heart defects. It offers several potential benefits including ease of handling, strength, flexibility, and lack of shrinkage after implantation. ${ }^{7}$ Associated with its use is the development of a neointimal covering on the surface that may proliferate and result in an excuberant peel formation.
This peel, consisting of granulation tissue, giant cells, and calcification, has resulted in intracardiac obstruction needing revision surgery. ${ }^{8-9}$ Dissection between the peel and bovine pericardium has not been previously described, although it is a recognised complication of peel formation associated with woven Dacron material. Woven Dacron has a tight weave that prevents tissue invasion and thus fibrous anchoring of the neointima. ${ }^{10}$ It is evident that in this case, despite the use of a biological material, there was a similar lack of tissue invasion permitting dissection to occur from the shearing forces applied at balloon dilatation with the creation of an obstructive flap.

A sudden rise in right ventricular pressure with bradycardia is known to occur in children undergoing right ventricular catheterisation. Such haemodynamic changes should be considered the result of acute dissection when occurring with balloon dilatation at the site of a previous cardiac surgical repair. An intimal flap may be identified radiologically. Management consists of initial stabilisation then immediate surgical exploration and appropriate repair. It may be possible at the time of catheterisation, to place a stent across the area of dissection to maintain patency until definitive surgical repair can be performed.

1 Zhao XH, Millar CD, Reitz BA, Shumway EN. Surgical repair of tetralogy of Fallot. $\mathcal{F}$ Thorac Cardiovasc Surg 1985;89:204-20.

2 Walsh EP, Rockenmacher S, Keane JF, Hougen TJ, Lock JE, Castaneda AR. Late results in patients with tetralogy 1062-7.

3 Pacifico $\mathrm{AD}$, Kirklin JK, Colvin ME, Kirklin JW. Tetralogy of Fallot: late results and reoperations. Semin Thorac Cardiovasc Surg 1990;2:108-16.

4 Rao PS, Fawsy ME, Solymar L, et al. Long term results of balloon pulmonary valvuloplasty of valvular pulmonic balloon pulmonary valvuloplasty of
stenosis. Am Heart $₹$ 1988;115:1291.

5 Lock JE, Keane JF, Fellows KE. The use of catheter intervention procedures for congenital heart disease. $\mathcal{f} \mathrm{Am}$ vention procedures for con
Coll Cardiol 1986;7:1420-3.

6 Radtke W, Lock JE. Balloon dilation. Pediatr Clin North Am 1990;37:193-224.

7 Crawford FA, Sade RM, Spinale F. Bovine pericardium for correction of congenital heart defects. Ann Thorac Surg 1986;41:602-5.

8 Cochran PR, McGeough EC. Bovine pericardium: a source of pulmonary venous obstruction in the mustard procedure. Ann Thorac Surg 1987;44:552-3.

9 Bullaboy CA. Bovine pericardium: another cautionary note [letter]. Ann Thorac Surg 1989;48:743.

10 Agarwal KC, Edwards WD, Feldt RH, Danielson GK Puga FJ, McGoon DC. Clinicopathological correlates of obstructed right sided porcine-valved extracardiac conduits. F Thorac Cardiovasc Surg 1981;81:591-601. 